\title{
Hemangiopericytoma in the Trigone of the Lateral Ventricle
}

-Case Report-

\author{
Ketan Desai, Trimurti NADKARni, Sudhir FATTEPURKAR, Atul GOEL, \\ Asha SHEnOY*, Arun CHITAlE**, and Girish MUZUMdAR***
}

\begin{abstract}
Departments of Neurosurgery and *Neuropathology, King Edward Memorial Hospital, Seth G. S. Medical College, Parel, Mumbai, India; ** Department of Electron Microscopy,

Jaslok Hospital and Research Centre, Dr. G. Deshmukh Marg, Mumbai, India;

*** Department of Histopathology, Bombay Hospital and Medical Research Centre, New Marine Lines, Mumbai, India
\end{abstract}

\begin{abstract}
A 40-year-old male presented with hemangiopericytoma in the lateral ventricle manifesting as headaches persisting for 6 months associated with vomiting and visual obscurations for one month. Computed tomography and magnetic resonance imaging of the brain showed a large tumor in the trigone of the right lateral ventricle. The highly vascular tumor was completely excised. The histological diagnosis was hemangiopericytoma. Hemangiopericytoma is rarely located in the lateral ventricle and is difficult to differentiate from meningioma by neuroimaging methods.
\end{abstract}

Key words: hemangiopericytoma, meningioma, trigone, lateral ventricle

\section{Introduction}

Hemangiopericytoma was first described as a subtype of angioblastic meningioma in $1928 .{ }^{3)} \mathrm{A}$ similar lesion was described as a vascular variant of a meningioma derived from meningothelial cells with angioblastic features. ${ }^{8)}$ The term "hemangiopericytoma" was first used for malignant vascular tumor consisting of cells resembling capillary pericytes (Zimmerman's pericytes) in the soft tissue of thigh, buttock, and retroperitoneum. ${ }^{23}$ The first case of primary intracranial hemangiopericytoma was reported in 1954.4)

Intracranial hemangiopericytomas are rare tumors that resemble meningiomas but behave more aggressively, with a tendency to metastasize and a higher propensity for recurrence. ${ }^{11)}$ Intracranial hemangiopericytoma accounts for $2 \%$ of all meningiomas, are more common in males, and $56-75 \%$ of cases occur between 38-42 years of age. ${ }^{1)}$ Most cases are located in the supratentorial compartment and less frequently in the posterior fossa or spine.1,10)

Received February 13, 2003; Accepted April 12, 2004
Other very rare sites are the sella (3 cases), ${ }^{12,16,18)}$ pineal region (3 cases), $\left.{ }^{14,21,22}\right)$ lateral ventricle (1 case), ${ }^{19)}$ and third ventricle (1 case). ${ }^{1)}$

Here we describe a case of hemangiopericytoma located in the trigone of the lateral ventricle.

\section{Case Report}

A 40-year-old male presented with a 6-month history of headaches, which were characteristically dull, aching, generalized, and intermittently throbbing in nature, and associated with features of raised intracranial pressure like vomiting and visual obscurations for the last month. Neurological examination revealed bilateral papilledema and left homonymous hemianopsia. No other central nervous system abnormalities were found including the whole spinal cord.

Computed tomography (CT) revealed a large, hyperdense, homogeneously enhanced mass located in the trigone of the right lateral ventricle, with dilation of the contralateral lateral ventricle (Fig. 1). Calcification was noted within the tumor. Magnetic resonance (MR) imaging showed the mass in the trigone of the right lateral ventricle as $7 \mathrm{~cm}$ in 
maximum diameter. The tumor was isointense on $\mathrm{T}_{1}$-weighted images (Fig. $2 \mathrm{~A}$ ) and was hypointense on $\mathrm{T}_{2}$-weighted images (Fig. 2B). After administration of gadolinium, the tumor showed intense homogeneous enhancement (Fig. 2C). Cerebral angiography was not performed.

The tumor was approached by a transcortical route through the superior parietal lobule. The tumor was characteristically reddish in color and bled profusely from the beginning of the excision.

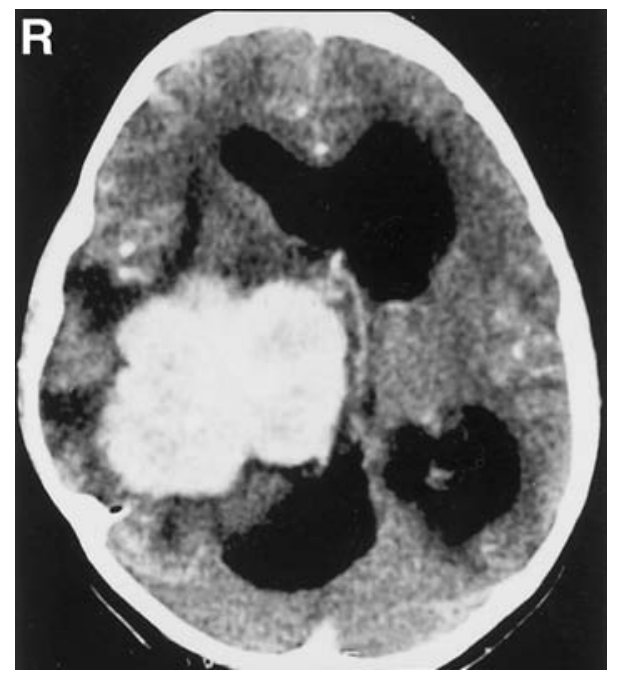

Fig. 1 Axial computed tomography scan showing a massive right trigonal mass, with dilation of the contralateral ventricle.
Profuse bleeding occurred from the numerous blood vessels within the tumor during the piecemeal excision. The tumor was supplied by the branches of the anterior and posterior choroidal arteries. The arterial feeders to the tumor arose from the choroid plexus. The intraoperative impression was meningioma. The tumor was completely excised. The blood loss during the surgery was 5 liters which was adequately replaced with fresh units of whole blood, platelets, and fresh frozen plasma. No hypotension or disseminated intravascular coagulopathy occurred during the surgery secondary to the profuse blood loss and transfusion. In the immediate postoperative period the patient was conscious and alert and had left hemiparesis.

Histological examination of the tumor revealed hemangiopericytoma, with the characteristic densely cellular neoplasm of oval and spindle cells, called pericytes, with prominent slit-like vascular spaces lined by endothelial cells (Fig. 3). No whorl formation or psammoma bodies were present, and no necrosis was found in the tumor. Mitotic activity was also minimal. These findings were consistent with the diagnosis of hemangiopericytoma. Immunohistochemical staining revealed the tumor cells were positive for vimentin and CD34, but negative for epithelial membrane antigen (EMA) and smooth muscle actin. Electron microscopy of the tumor showed elongated vascular channels surrounded by stacks of tumor cells. Basal lamina of variable thickness surrounded each tumor cell (Fig. 4). The histology, immunohistochemistry, and
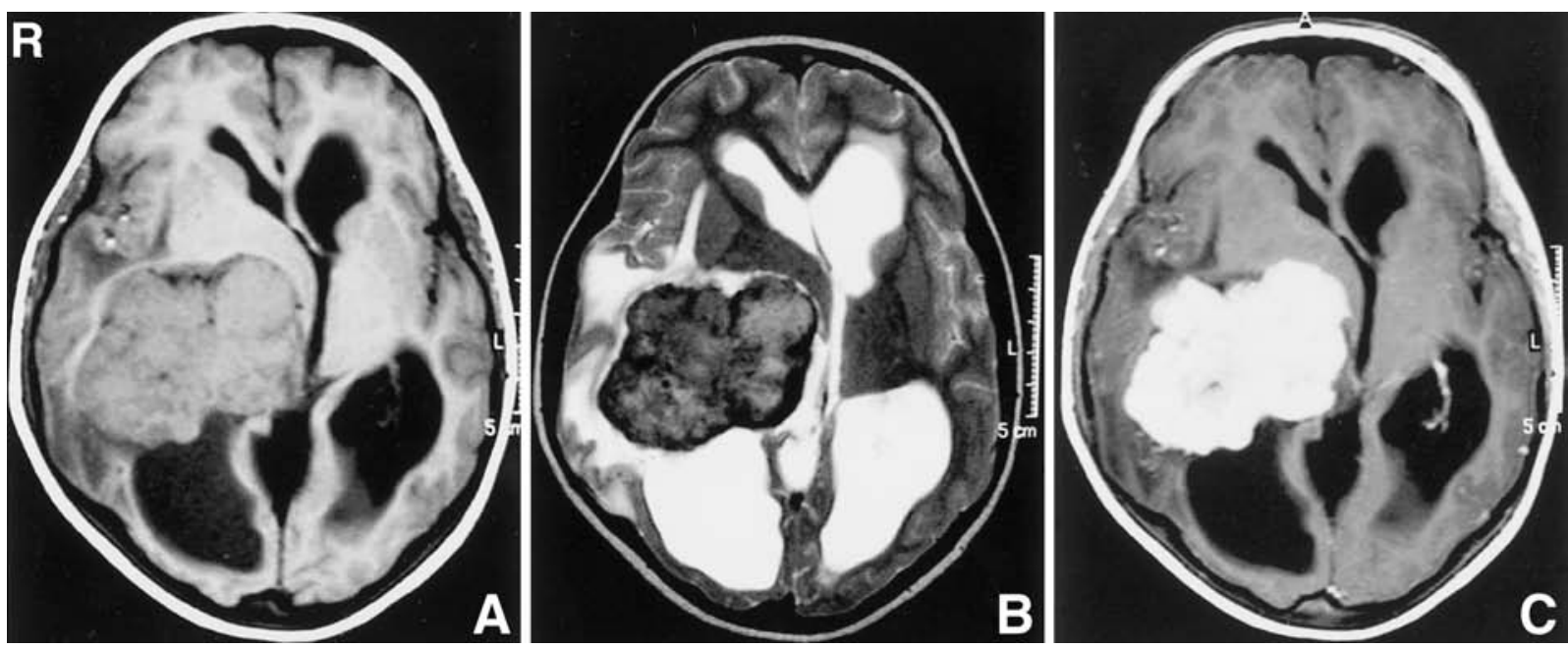

Fig. 2 (A) Preoperative axial $T_{1}$-weighted magnetic resonance (MR) image showing a large, isointense trigonal tumor. (B) $\mathrm{T}_{2}$-weighted $M R$ image showing the hypointense tumor. (C) Sagittal $T_{1}$-weighted $M R$ image with contrast medium showing intense enhancement of the tumor. 


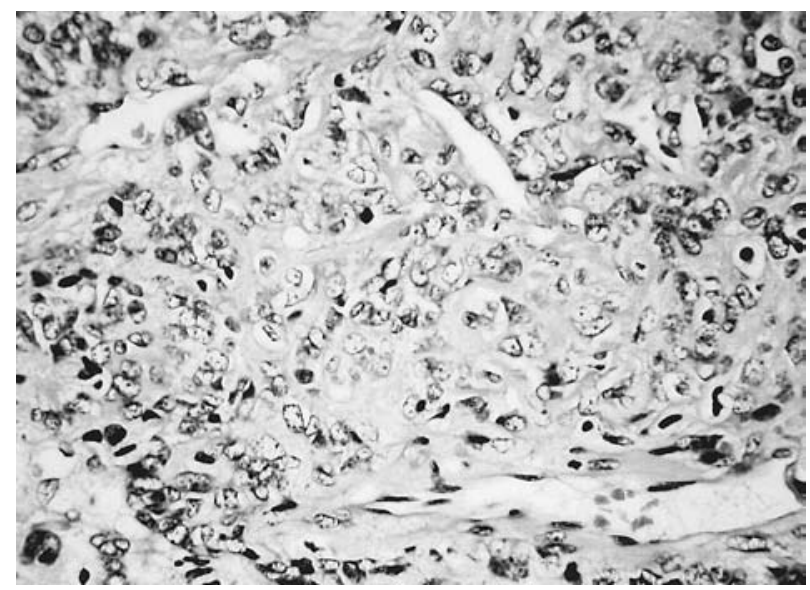

Fig. 3 Photomicrograph of the tumor showing slit-like and elongated thin-walled staghorn vessels surrounded by compactly arranged solid cellular spindle cells of pericytic lineage. HE stain, $\times 400$.
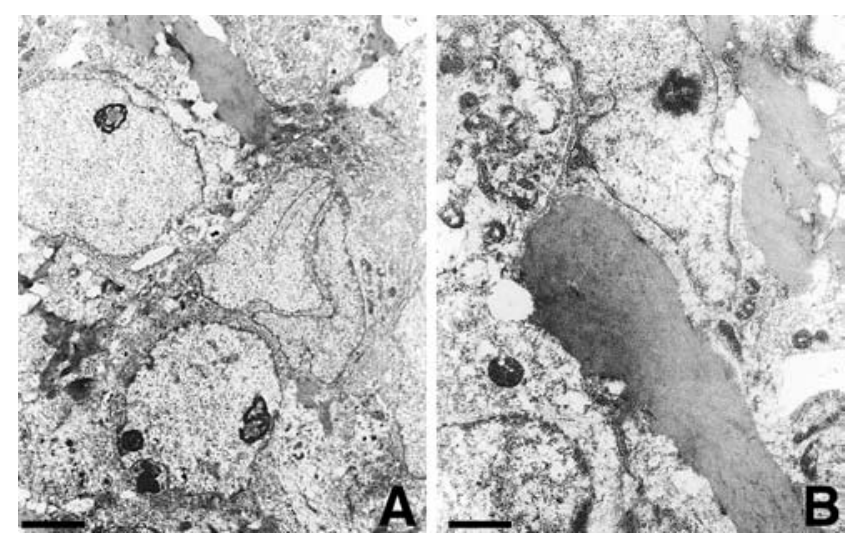

Fig. 4 Electron micrographs of the tumor showing basal lamina of variable thickness surrounding each tumor cell (A: bar $=2 \mu \mathrm{m}$ ) and two thick bands of basal lamina material (B: bar $=1 \mu \mathrm{m})$.

ultrastructural findings were consistent with hemangiopericytoma.

Adjuvant cranial radiotherapy was administered with a total dose of $60 \mathrm{~Gy}$ in 30 fractions in the immediate postoperative period. His left hemiparesis had recovered at 1-year follow up. There was no significant recovery of the left homonymous hemianopsia. Follow-up MR imaging at one year showed complete excision of the hemangiopericytoma (Fig. 5).

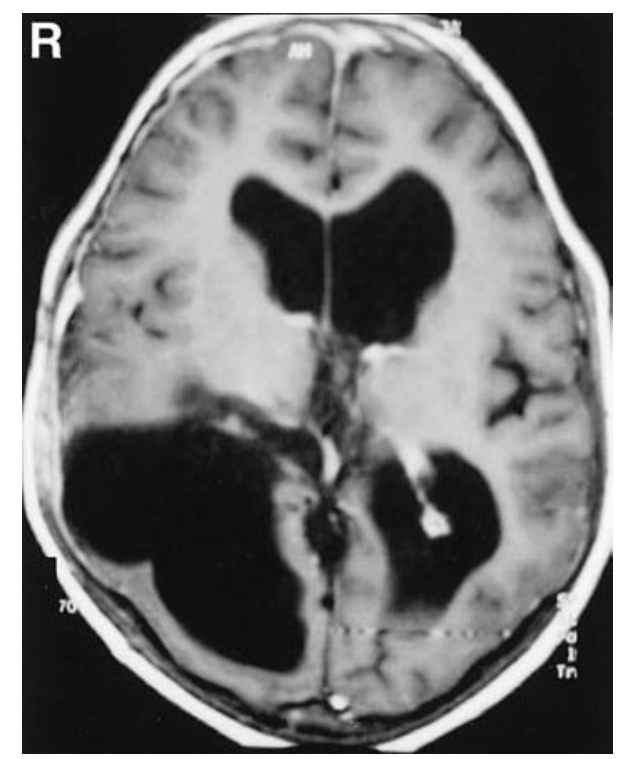

Fig. 5 Postoperative axial $\mathrm{T}_{1}$-weighted magnetic resonance image with contrast medium demonstrating complete excision of the intraventricular mass.

\section{Discussion}

The clinical features in our case were similar to any lateral ventricular tumor with headaches, features of raised intracranial pressure, and homonymous hemianopsia, which are common clinical findings in the majority of cases. ${ }^{19)}$ The findings of CT and MR imaging were very similar to the intraventricular meningioma, with brilliant enhancement after contrast administration. Angiography of hemangiopericytoma shows characteristic "corkscrew" vascular configurations with a long-lasting venous phase. The presence of calcification within the lesion by CT is strongly suggestive of meningioma rather than hemangiopericytoma. $\mathrm{T}_{2}$-weighted $\mathrm{MR}$ imaging often shows multiple flow voids in hemangiopericytoma. ${ }^{1,17)}$

Hemangiopericytoma is difficult to differentiate from meningioma by neuroimaging methods. Histology, immunohistochemistry, and electron microscopy findings are needed for the differential diagnosis. ${ }^{1,2,5,6,15)}$ Preoperative diagnosis of lateral ventricular hemangiopericytoma is extremely difficult and may pose a diagnostic dilemma based on the neuroimaging and gross appearances. Immunohistochemistry can differentiate hemangiopericytomas from meningiomas by showing positive staining for CD34 and vimentin. ${ }^{5,6,13)}$ Hemangiopericytomas show negative reaction to EMA and cytokeratin. ${ }^{13)}$ Connexin proteins form 
gap junctions in human arachnoid villi and meningiomas. Therefore, connexin expression is a useful marker for the differentiation of meningioma and hemangiopericytoma. ${ }^{2}$ The ultrastructure of hemangiopericytoma shows marked differences from those of syncytial and transitional meningiomas. ${ }^{5)}$ The tumor cells are plump and the cytoplasmic edges are blunt, but lack the complex cytoplasmic interdigitations and the desmosomes seen in meningiomas. Intensely electron-dense material fills the extracellular spaces, which appears as thickened basal lamina material. The plasma membranes of adjacent cells are closely opposed in some areas. ${ }^{5}$

Hemangiopericytomas are described as arising from pericytes, which are mesenchymal cells with contractile properties similar to the smooth muscle cells located in the walls of the capillaries external to the endothelial cells. These pericytes are unrelated to either meningioma cells or the progenitor arachnoid cells. Intraventricular hemangiopericytomas probably originate from the pericytes found within the tela choroidea or the stroma of the choroid plexus. ${ }^{1)}$

Intracranial hemangiopericytoma is an aggressive neoplasm with high malignant potential and incidence of recurrences. ${ }^{1)}$ The principal treatment is radical or total excision, irrespective of the location in the brain, followed by radiotherapy. Survival is correlated with more aggressive primary resection and postoperative radiotherapy. ${ }^{1,9)}$ Hemangiopericytoma is amongst the very few primary intracranial tumors to metastasize outside of the central nervous system. The most commonly encountered sites of metastasis are bone, followed by the lung and liver, and rarely the pancreas and spleen. ${ }^{10)}$ The rates of distant metastasis at 5,10 , and 15 years are approximately $13 \%, 33 \%$, and $64 \%$, respectively. The median recurrence-free interval is approximately 50 months. The 5-, 10-, and 15-year recurrence rates are $65 \%, 76 \%$, and $87 \%$, respectively. ${ }^{10)}$ The time interval between recurrences shortens with each operation for recurrent hemangiopericytoma. Irrespective of the extent of the surgical excision, radiotherapy is strongly recommended. Radiation helps to reduce the tumor size, decrease the chance of distant metastasis, and increase the recurrence-free interval. ${ }^{1)}$ Radiosurgery has been proposed as adjuvant therapy to treat selected patients with small and medium intracranial hemangiopericytomas that occur after surgery or radiation treatment. ${ }^{1,7,20)}$

Our present case of hemangiopericytoma in the trigone of the lateral ventricle is extremely rare. Histological, immunohistochemical, and ultrastructural examination of lateral ventricular heman- giopericytoma is mandatory as the neuroimaging differentiation from meningioma is difficult. Total excision is the ideal surgical option. Postoperative radiotherapy is recommended as the incidences of recurrence and distant metastases are high.

\section{References}

1) Abrahams J, Forman MS, Lavi E, Goldberg H, Flamm ES: Hemangiopericytoma of the third ventricle. Case report. J Neurosurg 90: 359-362, 1999

2) Arishima H, Sato K, Kubota T: Immunohistochemical and ultrastructural study of gap junction proteins connexin 26 and 43 in human arachnoid villi and meningeal tumors. J Neuropathol Exp Neurol 61: 1048-1055, 2002

3) Bailey P, Cushing H, Eisenhardt L: Angioblastic meningiomas. Arch Pathol Lab Med 6: 953-990, 1928

4) Begg CF, Garret R: Hemangiopericytoma occurring in the meninges. Case report. Cancer 7: 602-606, 1954

5) Bruner JM, Tien RD, Enterline DS: Tumors of the meninges and related tissues, in Bigner DD, McLendon RE, Bruner JM (eds): Russell and Rubinstein's Pathology of Tumors of the Nervous System, ed 6. New York, New York, Oxford University Press, 1998, pp 67-140

6) Chaubal A, Paetau A, Zoltick P, Miettinen M: CD34 immunoreactivity in nervous system tumors. Acta Neuropathol (Berl) 88: 454-458, 1994

7) Coffey RJ, Cascino TL, Shaw EG: Radiosurgical treatment of recurrent hemangiopericytomas of the meninges: preliminary results. J Neurosurg 78: 903-908, 1993

8) Cushing H, Eisenhardt L: Meningiomas: Their Classification, Regional Behavior, Life History and Surgical End Results. Springfield, Charles C Thomas, 1938, $100 \mathrm{pp}$

9) Du G, Zhou L, Li S, Mao Y, Chen H: Management of hemangiopericytomas in the central nervous system. Chin Med J (Engl) 114: 795-798, 2001

10) Guthrie BL, Ebersold MJ, Scheithauer BW, Shaw EG: Meningeal hemangiopericytoma: histological features, treatment, and long-term follow up of 44 cases. Neurosurgery 25: 514-522, 1989

11) Hara $M$, Aoyagi $M$, Nagashima $G$, Wakimoto $H$, Mikami T, Yamamoto S, Tamaki M, Hirakawa K: Recurrence in meningeal hemangiopericytomas. Surg Neurol 50: 586-591, 1998

12) Kanda Y, Mase M, Aihara N, Yamada K, Sugino F, Tateyama H: Sellar hemangiopericytoma mimicking pituitary adenoma. Surg Neurol 55: 113-115, 2001

13) Kroh H, Figols J, Sobieraj A: Intracranial hemangiopericytomas. Histological and immunohistochemical study. Folia Neuropathol 35: 121-127, 1997

14) Lesoin F, Bouchez B, Krivosic I, Delandsheer JM, Jomin M: Hemangiopericytic meningioma of the pineal region. Case report. Eur Neurol 23: 274-277, 1984 
15) Lolova I, Kamenova M: Hemangiopericytoma of the brain. Histological and histochemical study of four cases. J Neurosurg 39: 636-641, 1973

16) Mangiardi JR, Flamm ES, Cravioto H, Fisher B: Hemangiopericytoma of the pituitary fossa: case report. Neurosurgery 13: 58-62, 1983

17) Marc JA, Takei Y, Schechter MM, Hoffman JC: Intracranial hemangiopericytomas. Angiography, pathology, and differential diagnosis. Am J Roentgenol Radium Ther Nucl Med 125: 823-832, 1975

18) Morrison DA, Bibby K: Sellar and suprasellar hemangiopericytoma mimicking pituitary adenoma. Arch Ophthalmol 115: 1201-1203, 1997

19) Muttaqin Z, Uozumi T, Kuwabara S, Kiya K, Arita K, Ogasawara H, Takechi A: Intraventricular hemangiopericytoma-case report. Neurol Med Chir (Tokyo) 31: 662-665, 1991

20) Payne BR, Prasad D, Steiner M, Steiner L: Gamma surgery for hemangiopericytomas. Acta Neurochir (Wien) 142: 527-537, 2000

21) Sell JJ, Hart BL, Rael JR: Hemangiopericytoma: a rare pineal mass. Neuroradiology 38: 782-784, 1996

22) Stone JL, Cybulski GR, Rhee HL, Bailey OT: Excision of a large pineal region hemangiopericytoma (angioblastic meningioma, hemangiopericytoma type). Surg Neurol 19: 181-189, 1983

23) Stout AP, Murray MR: Hemangiopericytoma. A vascular tumor featuring Zimmerman's pericytes. Ann Surg 116: 26-33, 1942

Address reprint requests to: K. I. Desai, M.D., 7, Sunil Cooperative Housing Society, Simpoli Road, Borivali (West), Mumbai 400 092, India. e-mail: drketandesai@hotmail.com 